\title{
Dental education in the era of COVID-19 pandemic
}

\author{
Dr. Nashib Pandey ${ }^{1}$ \\ ${ }^{1}$ Department of Periodontics, Kantipur Dental College, Kathmandu, Nepal.
}

The outbreak of SARS-CoV-2 has pressurised nations across the globe for temporary closure of schools, colleges, universities, and other academic institutions. The consequence of different degrees of lockdown, social distancing, and quarantine has affected majority of the world's student population.1 Ultimately, the schools and universities have no other options rather than to start teaching and learning procedures through different online tools in the global situation of academic doom.2 Institutions around the world have turned to digital applications like Zoom, Microsoft Team, and Google Meet for the same.3 However, several challenges like limited access to the internet, frequent electricity power cuts, monetary crisis to buy electronic gadgets for facilitating online educational activities, and lack of monitoring quality assurance mechanisms may act as hindrances in implementing e-learning education. 4

The current unprecedented pandemic crisis, though a horrible situation to be in, still presents opportunities to empower students as well as academicians to cope with adverse conditions. So, to avoid the interruption to education as limited as possible, continuing the education through alternative learning pathways must be a top priority. 5 Needless to say, the pandemic has transformed the centuriesold, "chalk talk" teaching model to one driven by modern technology. However, unlike other disciplines, the syllabus

\footnotetext{
Correspondence:

Dr. Nashib Pandey

Department of Periodontics, Kantipur Dental College,

Kathmandu, Nepal.

email: nashibpandey@gmail.com

\section{Citation}

Pandey S. Impact of COVID-19 on Dental Education. J Nepal Soc Perio Oral Implantol. 2020;4(8):100
}

of dental education has allocated a greater number of hours for the practical and clinical learning. The skill transfer to the future doctors necessitates the physical rather than virtual presence of a mentor as well as mentee which needs some innovative ideas to be fulfilled through the online system of learning. This is the need of the hour.

Positive Impact of COVID-19 pandemic on the dental education:

- Digitalisation of education

- $\quad$ Future pandemic preparedness

- $\quad$ Pursue in-service career training

- Exposure of student, teachers, and parents to online education

- Skill development and training for online classes in the future

Negative Impact of COVID-19 pandemic on the dental education:

- Temporary closure of education institutions

- Disrupted board exams, assessments, current admissions, and enrollment cycle

- Irregularity in learning and skills development

- Inequality in access to e-education

- Anxiety and fear to resume dental colleges

- $\quad$ Limited time to complete the curriculum

- Confusion of students over their future careers

- Inadequate preparedness of academia for health emergencies-low access to technology, infrastructure, financial funds, trained human resources, etc.

- Lack of skillful training of e-learning and teaching in limited time

- Impediment in skill transfer through practical demonstrations

- $\quad$ Restriction to exchange of skill from foreign instructors

\section{REFERENCES}

1. Sahu P. Closure of Universities Due to Coronavirus Disease 2019 (COVID-19): Impact on Education and Mental Health of Students and Academic Staff. Cureus. 2020;12(4):e7541.

2. Eisenberg J, Escobar A. COVID-19: 10 steps for transferring your course online [internet]. World Economic Forum; Accessed: March 25, 2020. Available from: https://www.weforum.org/agenda/2020/03/covid-19-10-steps-online-learning/

3. Aririahu C. Zoom meetings vs Google Meet vs Microsoft Teams [internet]. Last updated July 27, 2020; Accessed: March 25, 2020 Available from: https://www.afterschoolafrica.com/49797/zoom-meetings-vs-google-meet-vs-microsoft-teams/

4. Yusuf BNM, Ahmad J. Are we Prepared Enough? A Case Study of Challenges in Online Learning in a Private Higher Learning Institution During The Covid-19 Outbreaks. Advances in Social Sciences Research Journal. 2020;7(5):205-12.

5. Broom D. Homeschooling during the coronavirus pandemic could change education forever, says the OECD World Economic Forum [internet]. [Accessed: March 25, 2020]. Available from: https://www.weforum.org/agenda/2020/04/coronavirus-homeschoolingtechnology-oecd/ 